International Journal of Wireless \& Mobile Networks (IJWMN) Vol. 4, No. 1, February 2012

\title{
Performance Evaluation OF AODV AND DSR ON-DEMAND Routing Protocols WiTh VARYING MANET SIZE
}

\author{
Nilesh P. Bobade ${ }^{1}$, Nitiket N. Mhala ${ }^{2}$ \\ ${ }^{1}$ Department of Electronics Engineering, Bapurao Deshmukh COE, Sevagram, \\ Wardha, M.S., India. \\ b_nilesh246@rediffmail.com \\ ${ }^{2}$ Department of Electronics Engineering, Bapurao Deshmukh COE, Sevagram, \\ Wardha, M.S., India. \\ nitiket_merediffmail.com
}

\begin{abstract}
A mobile ad hoc network (MANET) is a collection of wireless mobile nodes dynamically forming a network topology without the use of any existing network infrastructure or centralized administration. Routing is the process which transmitting the data packets from a source node to a given destination. The main procedure for evaluating the performance of MANETs is simulation. The on-demand protocol performs better than the table-driven protocol. Different methods and simulation environments give different results. It is not clear how these different protocols perform under different environments. One protocol may be the best in one network configuration but the worst in another. In this paper an attempt has been made to compare the performance of on demand reactive routing protocols i.e. Ad hoc On Demand Distance Vector (AODV) and Dynamic Source Routing (DSR). As per our findings the differences in the protocol mechanics lead to significant performance differentials for both of these protocols. Always the network protocols were simulated as a function of mobility, but not as a function of network density. In our paper the performance of AODV and DSR is evaluated with respect to performance metrics like Packet Delivery Fraction (PDF), Average end-to-end delay, Normalized Routing Load (NRL) and throughput by varying network size up to 50 nodes. These simulations are carried out using the NS-2 which is the main network simulator, NAM (Network Animator), AWK (post processing script). Our results presented in this research work demonstrate the concept AODV and DSR routing protocols w.r.t. MANET size in an Ad hoc environment.
\end{abstract}

\section{KEYWORDS}

MANET, AODV, DSR, Performance Metrics, NS-2.34\& Simulation

\section{INTRODUCTION}

A Mobile Ad hoc Network (MANET) is a system of wireless mobile nodes which can freely and dynamically self-organize and co-operative in to arbitrary and temporary network topologies, allowing peoples and devices to communicate without any pre-existing communication architecture. Each node in the ad hoc network acts as a router, forwarding data packets for other nodes. A central challenge in the design of mobile ad hoc networks is the development of routing protocols that can efficiently find the transmission paths between two communicating nodes. The ad hoc networks are very flexible and suitable for several types of applications due to its feature like they allow the establishment of temporary communication without any pre-installed infrastructure. With newly emerging radio technologies, e.g. IEEE 802.11and Bluetooth, the realization of multimedia applications over mobile ad-hoc networks becomes more realistic. Our goal is to carry out a systematic performance study of an on demand routing protocol AODV [1, 
International Journal of Wireless \& Mobile Networks (IJWMN) Vol. 4, No. 1, February 2012

14] and DSR [1] for ad hoc networks. However our performance evaluation is based on varying node density in the Mobile ad hoc Network. Generally the network protocols were simulated as a function of pause time (node mobility), but not as a function of network size. The rest of the paper is organized as follows: The related work is provided in section 2. The AODV and DSR routing protocol Description are summarized in section 3 and 4 resp. The simulation environment and performance metrics are described in Section 5. We present the simulation results and observation in section 6 and the conclusion is presented in section 7 .

\section{RELATED WORK}

Several researchers have done the quantitative and qualitative analysis of Ad hoc Routing Protocols by means of different performance parameters. Also they have used different simulators for this purpose.

1) J Broch et al. [1] performed experimental performance comparison of both proactive and reactive routing protocols. In their NS-2 simulation, a network density of 50 nodes with varying pause times and various movement patterns were chosen.

2) Jorg D.O. [3] studied the behavior of different routing protocols for the changes of network topology which resulting from link breaks, node movement, etc. In his paper, performance of routing protocols was evaluated by varying number of nodes. But he did not investigate the performance of protocols under high mobility, large number of traffic sources and larger number of nodes in the network which may lead to congestion situations.

3) Khan et al. [4] studied and compared the performance of routing protocols by using NCTUns network simulator. In their paper, performance of routing protocols was evaluated by varying number of nodes in multiples of 5 in the ad hoc network. The simulations were carried out for 70 seconds of the simulation time. The packet size was fixed to 1400 bytes.

4) Arunkumar $B R$ et al. Authors perform simulations by using NS-2 simulator [13]. Their studies have shown that reactive protocols perform better than table driven (proactive) protocols.

5) S. Gowrishanker et al [9] performed the analysis of OLSR and AODV by using NS-2, the simulation period for each scenario was 900 seconds and the simulated mobility network area was $800 \mathrm{~m}$ x $500 \mathrm{~m}$. In each simulation scenario, the nodes were initially located at the center of the simulation region. The nodes start moving after the first 10 seconds of simulated time. In it, the application used to generate is CBR traffic and IP is used as Network layer protocol.

6) $N$ Vetrivelan \& Dr. A V Reddy [10] analyzed the performance differentials using varying network density and simulation times. They performed two simulation experiments for $10 \& 25$ nodes with simulation time up to $100 \mathrm{sec}$.

7) S. P. Setty et.al.[6] evaluated the performance of existing wireless routing protocol AODV in various nodes placement models like Grid, Random and Uniform using QualNet 5.0.

\section{AODV Routing Protocol Description}

Ad hoc On Demand Distance Vector (AODV) [14] is a reactive routing protocol which initiates a route discovery process only when it has data packets to transmit and it does not have any route path towards the destination node, that is, route discovery in AODV is called as on-demand. AODV uses sequence numbers maintained at each destination to determine freshness of routing information and to avoid the routing loops that may occur during the routing calculation process. All routing packets carry these sequence numbers. 
International Journal of Wireless \& Mobile Networks (IJWMN) Vol. 4, No. 1, February 2012

\subsection{Route Discovery Process}

During a route discovery process, the source node broadcasts a route query packet to its neighbors. If any of the neighbors has a route to the destination, it replies to the query with a route reply packet; otherwise, the neighbors rebroadcast the route query packet. Finally, some query packets reach to the destination.

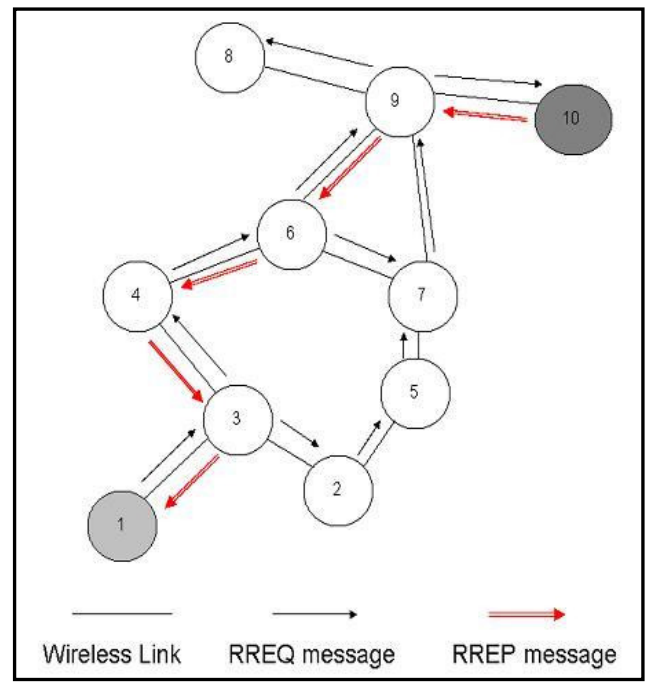

Figure 1. AODV Route Discovery Process

Figure 1 shows the route discovery process from source node1 to destination node 10 . At that time, a reply packet is produced and transmitted tracing back the route traversed by the query packet as shown in Figure 1.

\subsection{AODV Route Message Generation}



Figure 2. AODV Route Error message generation 
International Journal of Wireless \& Mobile Networks (IJWMN) Vol. 4, No. 1, February 2012

The route maintenance process in AODV is very simple. When the link in the communication path between node 1 and node 10 breaks the upstream node that is affected by the break, in this case node 4 generates and broadcasts a RERR message. The RERR message eventually ends up in source node 1 . After receiving the RERR message, node 1 will generate a new RREQ message (Figure 2).

\subsection{AODV Route Maintenance Process}

Finally, if node 2 already has a route to node 10, it will generate a RREP message, as indicated in Figure 3. Otherwise, it will re-broadcast the RREQ from source node 1 to destination node 10 as shown in Figure 3.

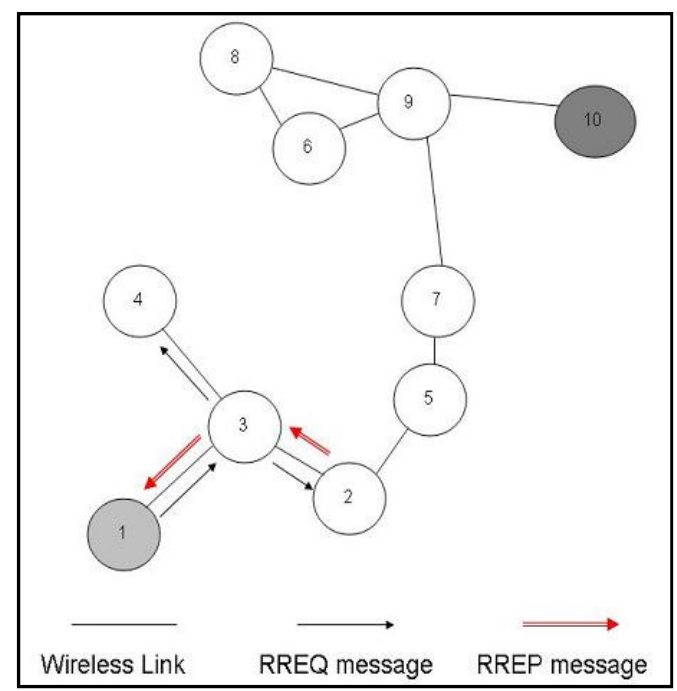

Figure 3. AODV Route Maintenance Process

\section{DSR Routing Protocol Description}

The Dynamic Source Routing (DSR) protocol is a reactive routing protocol based on source routing. In the source routing, a source determines the perfect sequence of nodes with which it propagate a packet towards the destination. The list of intermediate nodes for routing is explicitly stored in the packet's header.

In DSR, every mobile node needs to maintain a route cache where it caches source routes. When a source node wants to send a packet to some other intermediate node, it first checks its route cache for a source route to the destination for successful delivery of data packets. In this case if a route is found, the source node uses this route to propagate the data packet otherwise it initiates the route discovery process. Route discovery and route maintenance are the two main features of the DSR protocol.

\subsection{Route Discovery}

For route discovery, the source node starts by broadcasting a route request packet that can be received by all neighbor nodes within its wireless transmission range. The route request contains the address of the destination host, referred to as the target of the route discovery, the source's address, a route record field and a unique identification number (Figure 4). At the end, the source node should receive a route reply packet with a list of network nodes through which it should transmit the data packets that is supposed the route discovery process was successful $[3,16]$. 
International Journal of Wireless \& Mobile Networks (IJWMN) Vol. 4, No. 1, February 2012

During the route discovery process, the route record field is used to contain the sequence of hops which already taken. At start, all senders initiate the route record as a list with a single node containing itself. The next intermediate node attaches itself to the list and so on. Each route request packet also contains a unique identification number called as request_id which is a simple counter increased whenever a new route request packet is being sent by the source node. So each route request packet can be uniquely identified through its initiator's address and request_id. When a node receives a route request packet, it is important to process the request in the following given order. This way we can make sure that no loops will occur during the broadcasting of the packets.



Figure 4. Building of the record during route discovery in DSR

If the pair < source node address, request_id > is found in the list of recent route requests, the packet is discarded.

If the host's address is already listed in the request's route record, the packet is also discarded. This indicates removal same request that arrive by using a loop.

If the destination address in the route request matches the host's address, the route record field contains the route by which the request reached this host from the source node. A route reply packet is sent back to the source node with a copy of this route.

Otherwise, add this node's address to the route record field and re-broadcast this packet.

A route reply is sent back either if the request packet reaches the destination node itself, or if the request reaches an intermediate node which has an active route4 to the destination in its route cache. The route record field in the request packet indicates the sequence of hops which was considered. If the destination node generating the route reply, it just takes the route record field of the route request and puts it into the route reply. If the responding node is an intermediate node, it attaches the cached route to the route record and then generates the route reply (Figure 5). 


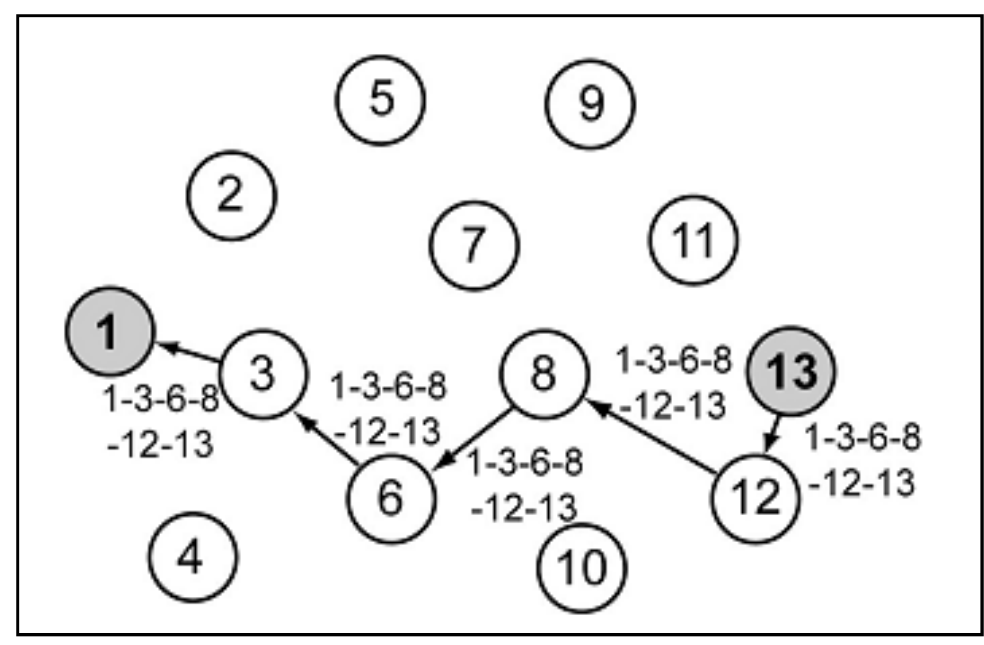

Figure 5. Propagation of the route reply in DSR

Sending back route replies can be processed with two different ways: DSR may use symmetric links. In the case of symmetric links, the node generating the route reply just uses the reverse route of the route record. When using asymmetric links, the node needs to initiate its own route discovery process and back the route reply on the new route request.

\subsection{Route Maintenance}

Route maintenance can be accomplished by two different processes:

Hop-by-hop acknowledgement at the data link layer

End-to-end acknowledgements

Hop-by-hop acknowledgement is the process at the data link layer which allows an early detection and re-transmission of lost packets. If the data link layer determines a fatal transmission error, a route error packet is being sent back to the sender of the packet. The route error packet contains the information about the address of the node detecting the error and the host's address which was trying to transmit the packet. Whenever a node receives a route error packet, the hop is removed from the route cache and all routes containing this hop are truncated at that point.

When wireless transmission between two hosts does not process equally well in both directions, end-to-end acknowledgement may be used. As long as a route exists, the two end nodes are able to communicate and route maintenance is possible. In this case, acknowledgements or replies on the transport layer used to indicate the status of the route from one host to the another. However, with end-to-end acknowledgement it is not possible to find out the hop which has been in error.

\section{Simulation ENVIRONMENT}

\subsection{Simulation Model}

Here we give the significance for the evaluation of performance of Ad Hoc routing protocol AODV with varying the number of mobile nodes. The network simulations have been done using network simulator NS-2 [13]. The network simulator NS-2 is discrete event simulation software for network simulations which means it simulates events such as sending, receiving, forwarding and dropping packets. The latest version, ns-allinone-2.34, supports simulation for routing protocols for ad hoc wireless networks such as AODV, DSDV, TORA, and DSR. NS-2 
International Journal of Wireless \& Mobile Networks (IJWMN) Vol. 4, No. 1, February 2012

is written in $\mathrm{C}++$ programming language with Object Tool Common Language (OTCL). Although NS-2. 34 can be built on different platforms, for this paper, we chose a Linux platform i.e. FEDORA 7, as Linux offers a number of programming development tools that can be used with the simulation process. To run a simulation with NS-2.34, the user must write the OTCL simulation script. We get the simulation results in an output trace file and here, we analyzed the experimental results by using the awk command (Figure $8 \& 9$ ). The performance parameters are graphically visualized in XGRAPH v12.1(Figure 10, 11, 12 \& 13). NS-2 also offers a visual representation of the simulated network by tracing nodes movements and events and writing them in a network animator (NAM) file (Figure $6 \& 7$ ).

\subsection{Simulation Parameters}

In our work, we consider a network of nodes placing within a $1000 \mathrm{~m}$ X $1000 \mathrm{~m}$ area. The performance of AODV and DSR is evaluated by keeping the network speed and pause time constant and varying the network size (number of mobile nodes). Table 1 shows the simulation parameters used in this evaluation.

Table 1. Parameters values for AODV and DSR Simulation

\begin{tabular}{|c|c|}
\hline \multicolumn{2}{|c|}{ Simulation Parameters } \\
\hline Simulator & NS-2.34 \\
\hline Protocols & AODV and DSR \\
\hline Simulation duration & 200 seconds \\
\hline Simulation area & $1000 \mathrm{~m} \times 1000 \mathrm{~m}$ \\
\hline Number of nodes & $5,10,15,20,25,30,35,40,45,50$ \\
\hline Transmission range & $250 \mathrm{~m}$ \\
\hline Movement model & Random Waypoint \\
\hline MAC Layer Protocol & IEEE 802.11 \\
\hline Pause Time & $100 \mathrm{sec}$ \\
\hline Maximum speed & $20 \mathrm{~m} / \mathrm{s}$ \\
\hline Packet rate & 4 packets/sec \\
\hline Traffic type & CBR (UDP) \\
\hline Data Payload & 512 bytes/packet \\
\hline
\end{tabular}

\subsection{Performance Metrics}

While analyzed the AODV and DSR protocols, we focused on four performance metrics for evaluation which are Packet Delivery Fraction (PDF), Average End-to-End Delay, Normalized Routing Load (NRL) and Throughput.

\subsubsection{Packet delivery fraction}

Packet delivery fraction (PDF) is the fraction of all the received data packets successfully at the destinations over the number of data packets sent by the CBR sources.

\subsubsection{Average End to end delay}

It is the average time from the transmission of a data packet at a source node until packet delivery to a destination which includes all possible delays caused by buffering during route discovery process, retransmission delays, queuing at the interface queue, propagation and transfer times of data packets. 
International Journal of Wireless \& Mobile Networks (IJWMN) Vol. 4, No. 1, February 2012

\subsubsection{Normalized Routing Load}

The normalized routing load (NRL) is as the ratio of all routing control packets sent by all nodes to the number of received data packets at the destination nodes.

\subsubsection{Throughput}

It is the average number of messages successfully delivered per unit time or it is the average number of bits delivered per second.

\section{Simulation Results \& ObesRVATion}

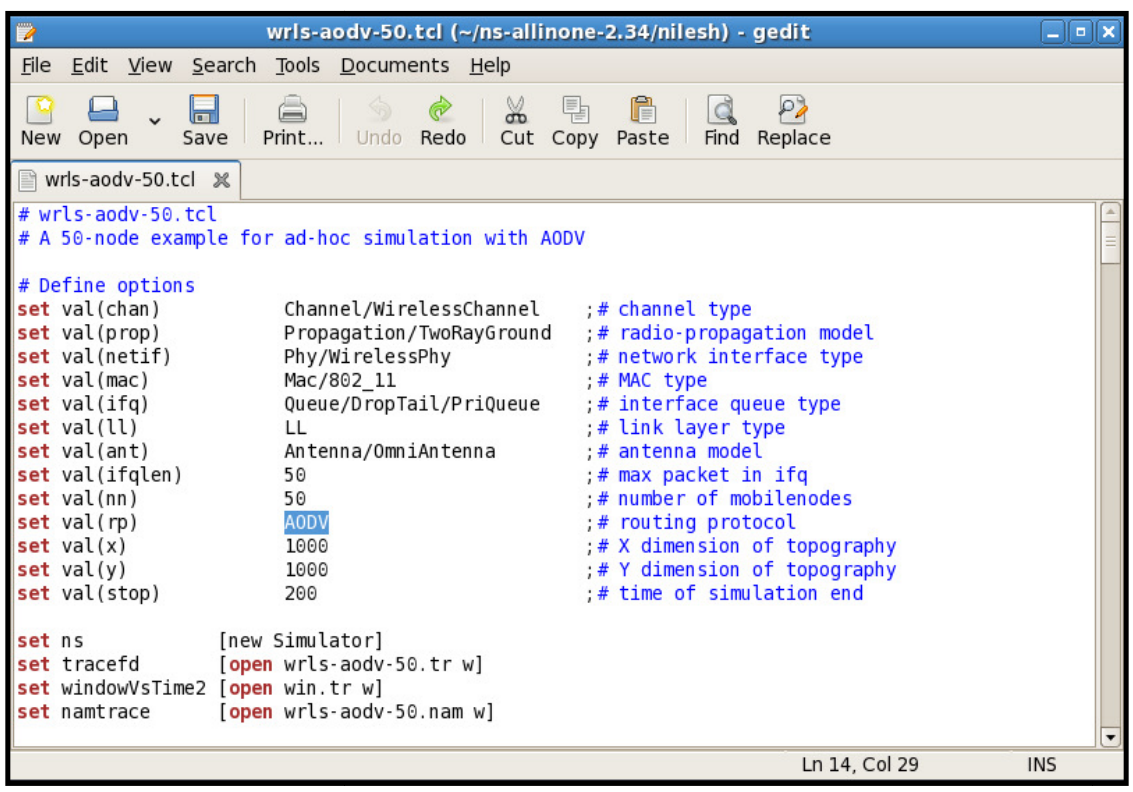

Figure 6. Screenshot of AODV Tcl script

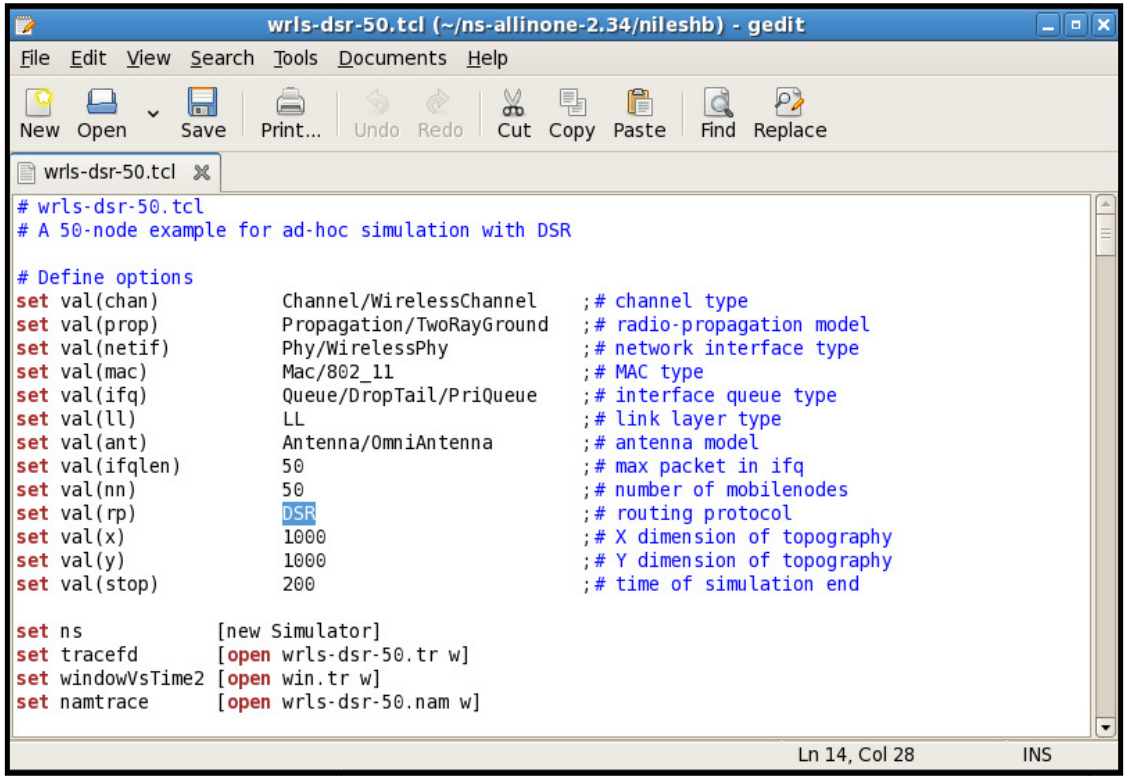

Figure 7. Screenshot of DSR Tcl script 
International Journal of Wireless \& Mobile Networks (IJWMN) Vol. 4, No. 1, February 2012

Figure 6 and figure 7 show the screenshots of AODV and DSR Tcl script. The results after simulation are viewed in the form of line graphs. The performance of AODV and DSR based on the varying the network size i.e. no. of nodes is done on parameters like packet delivery fraction, average end-to-end delay, normalized routing load and throughput.

Figure 8 and figure 9 show the creation of clusters with 50 mobile nodes for AODV and DSR respectively as it is shown in the NAM console which is a built-in program in NS-2-allinone package after the end of the simulation process.

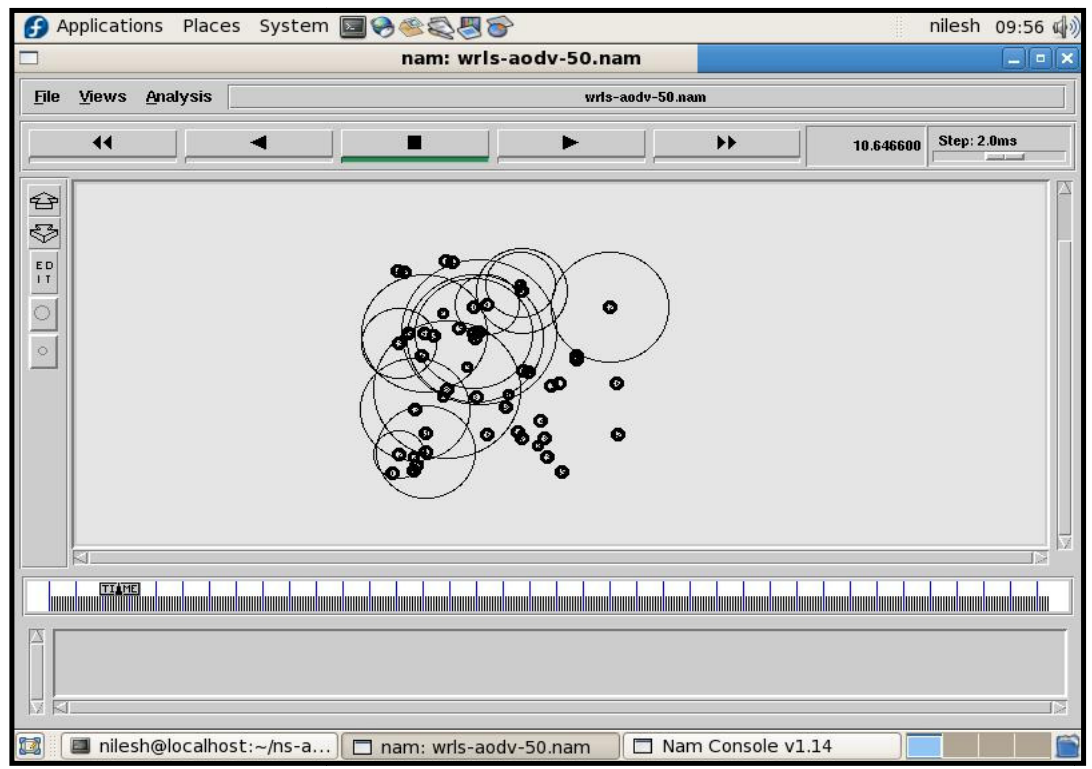

Figure 8. AODV with 50 nodes: Route Discovery

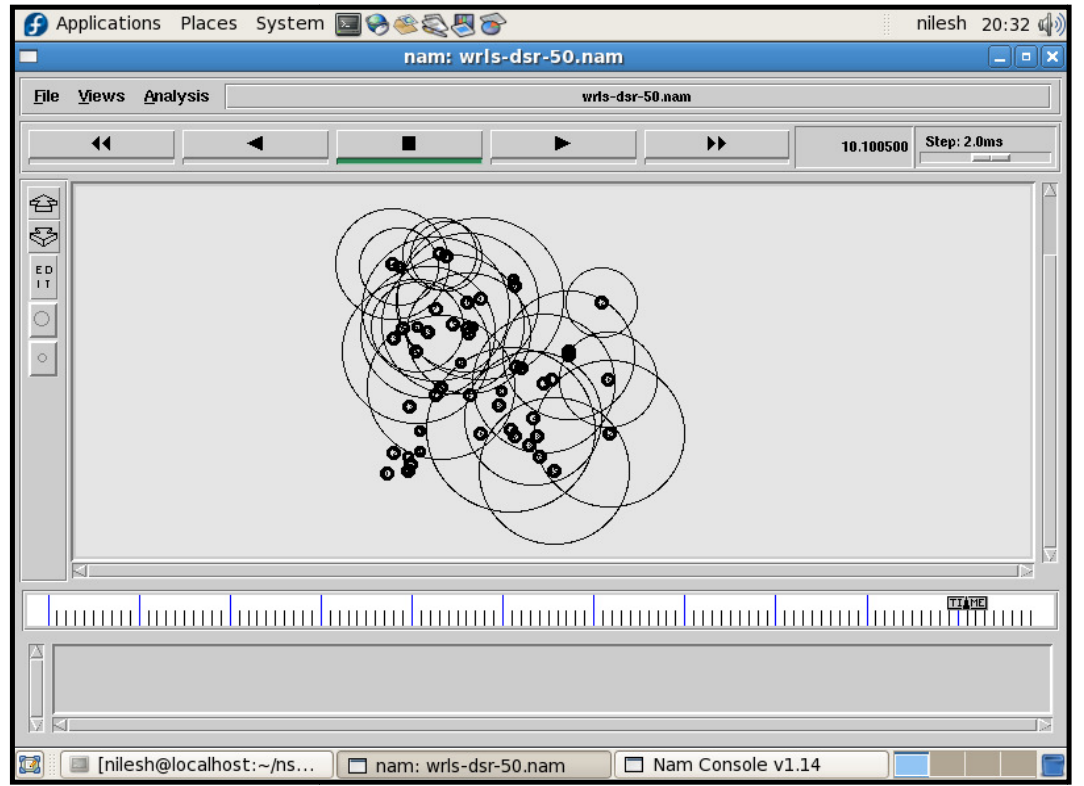

Figure 9. DSR with 50 nodes: Route Discovery 
International Journal of Wireless \& Mobile Networks (IJWMN) Vol. 4, No. 1, February 2012

Figure 10 and 11 shows the calculation of send packets, received packets, packet delivery fraction, average end-to-end delay, normalized routing load and etc. for AODV and DSR simulation resp. (50 nodes) by running AWK script for it.

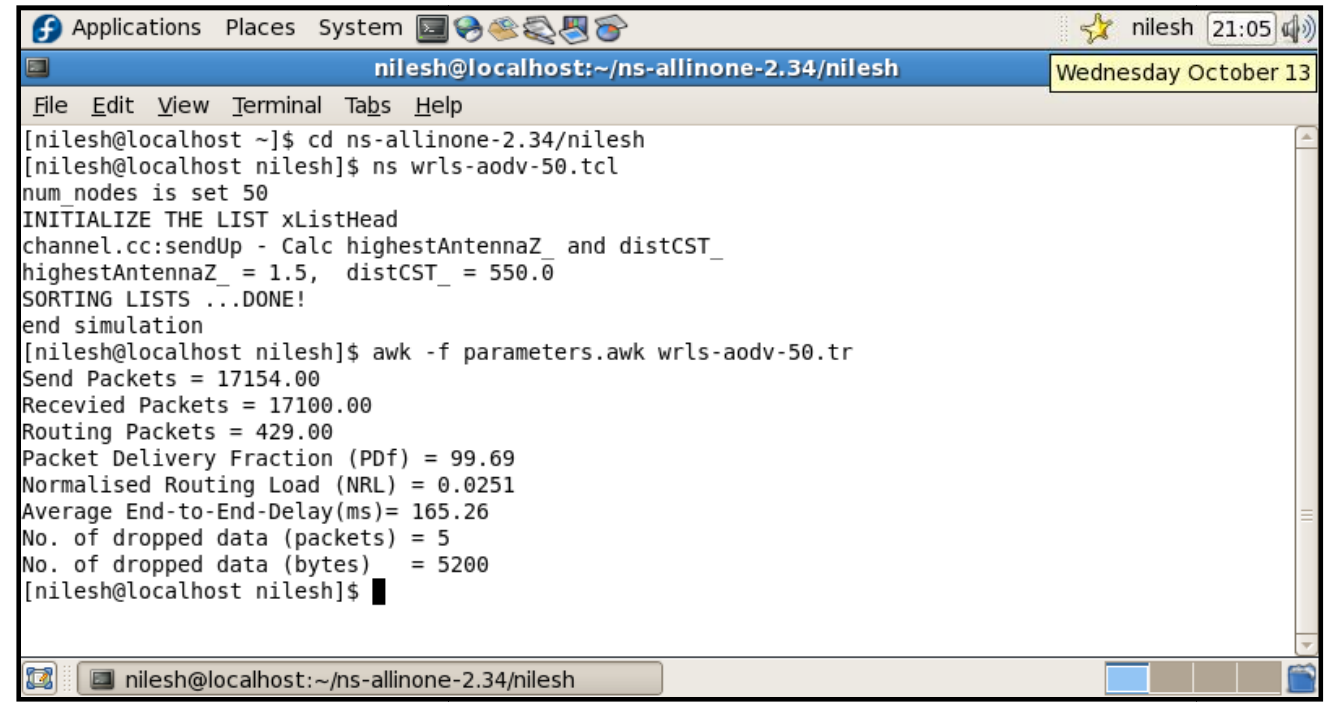

Figure 10. Screenshot of the results of performance metrics for AODV simulation

\begin{tabular}{|c|c|}
\hline nilesh@localhost; /ns-allinone-2,34/nileshb & $-\square x$ \\
\hline File É dit View Ierminal Tabss $\underline{\text { Help }}$ & \\
\hline $\begin{array}{l}\text { [nilesh@localhost } \sim \text { ] } \mathrm{cd} \text { ns-allinone-2.34/nileshb } \\
\text { [nilesh@localhost nileshb]\$ awk -f dsrparameters.awk wrls-dsr-50.tr } \\
\text { Send Packets }=30.00 \\
\text { Recevied Packets }=20.00 \\
\text { Routing Packets }=77.00 \\
\text { Packet Delivery Fraction (PDf) }=66.67 \\
\text { Normalised Routing Load (NRL) }=3.8500 \\
\text { Average End-to-End-Delay }(\mathrm{ms})=138.52 \\
\text { [nilesh@localhost nileshb] } \$\end{array}$ & $\theta$ \\
\hline
\end{tabular}

Figure 11. Screenshot of the results of performance metrics for DSR simulation

Figure 12 highlights the relative performance of AODV and DSR. When looking at the packet delivery ratio, it can easily be seen that AODV perform much better than DSR. AODV delivers a greater percentage of the originated data i.e. almost $100 \%$. The low packet delivery fraction of DSR may be explained by the aggressive route caching built into this protocol. Further it is observed that the performance of AODV is consistently uniform between $99.5 \%$ \& $99.7 \%$. 
International Journal of Wireless \& Mobile Networks (IJWMN) Vol. 4, No. 1, February 2012



Figure 12. Packet Delivery Fraction for AODV and DSR with varying no. of Mobile Nodes

From figure 13, it is clear that the average delay of AODV is higher than DSR. The performance of AODV is almost uniform (below $180 \mathrm{~ms}$ ) except for 40 nodes.

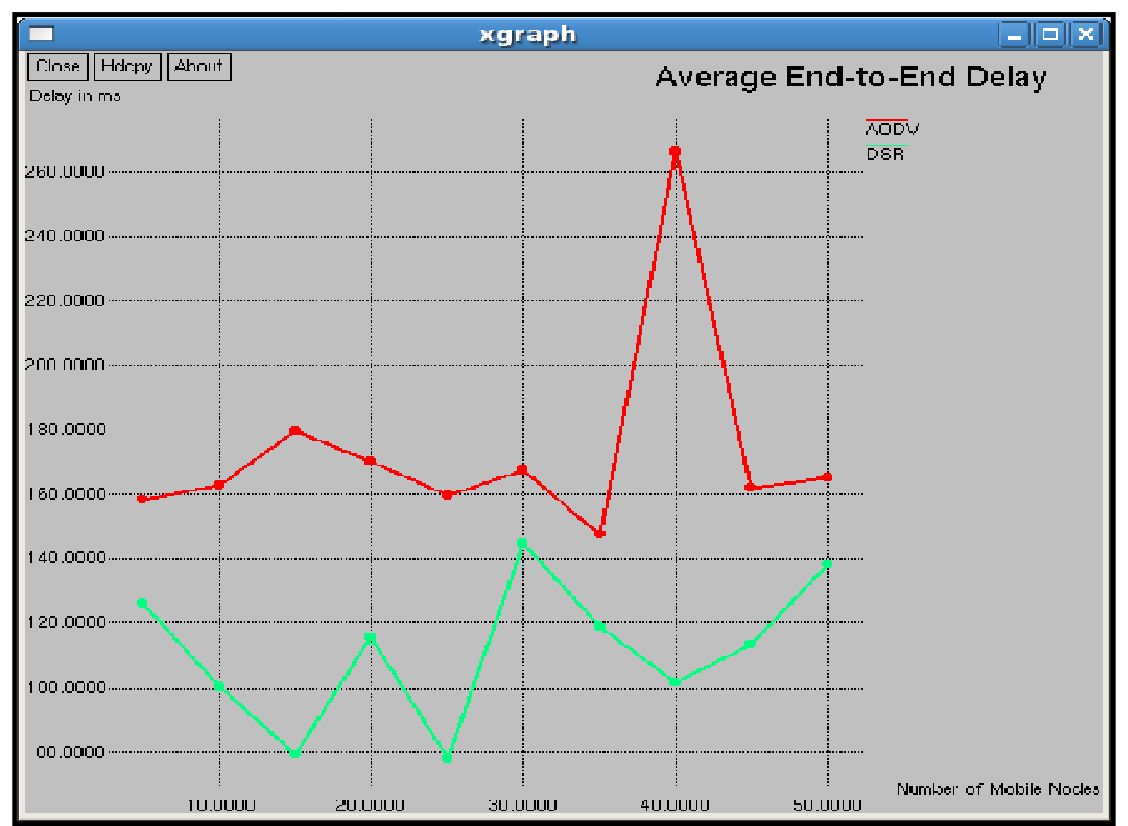

Figure 13. Average End-to-End Delay for AODV and DSR with varying no. of Mobile Nodes

From figure 14, we can observe that AODV demonstrates significantly lower routing load than DSR. It is almost the consistent. 
International Journal of Wireless \& Mobile Networks (IJWMN) Vol. 4, No. 1, February 2012

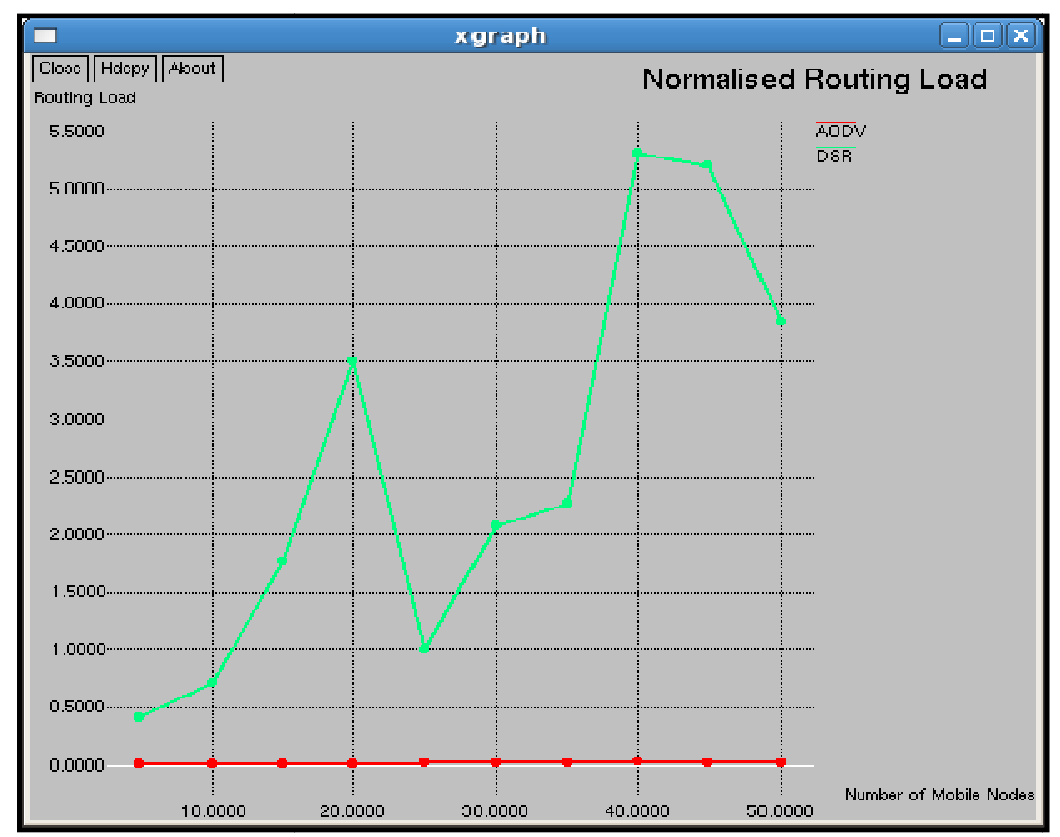

Figure 14. Normalized routing Load for AODV and DSR with varying no. of Mobile Nodes

In the AODV routing protocol, when the number of nodes increases, initially throughput increases due to availability of large number of routes but after a certain limit throughput becomes nearly stable as shown in Figure 15. DSR also gives the consistent throughput but slightly smaller than AODV.

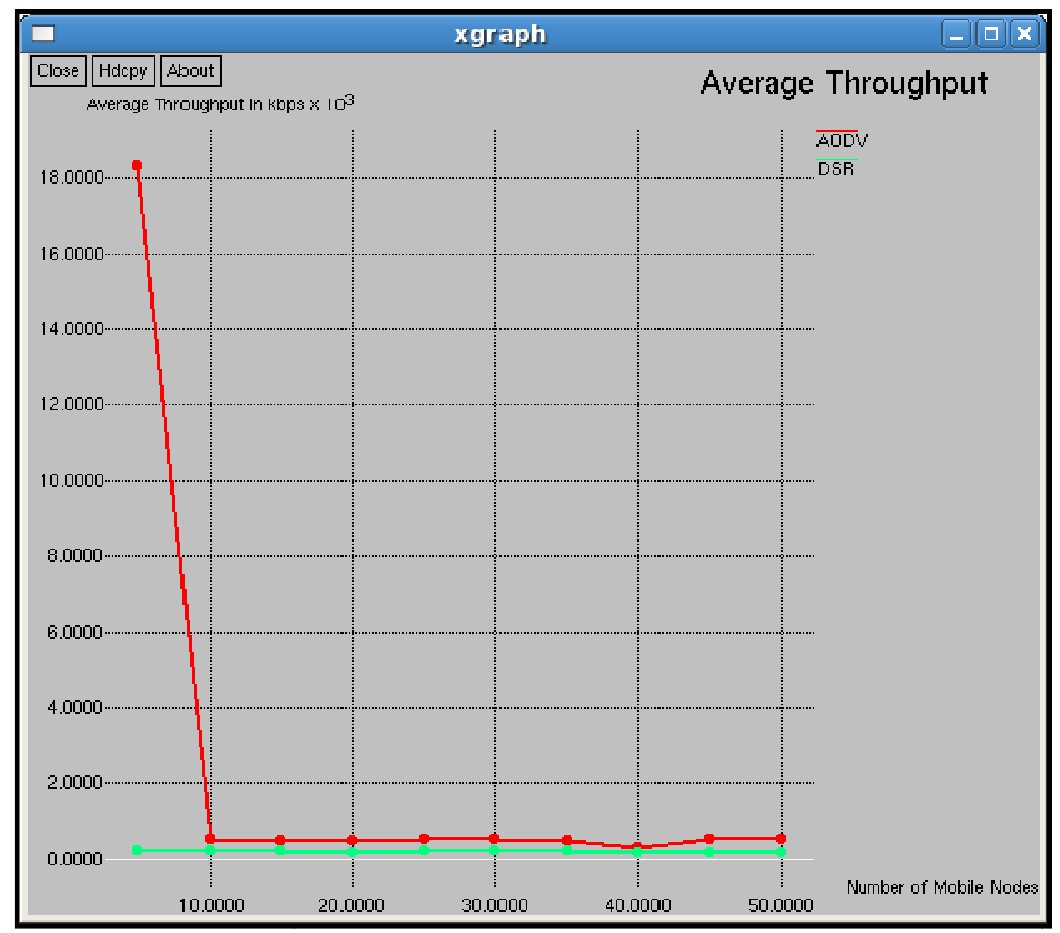

Figure 15. Throughput for AODV and DSR with varying no. of Mobile Nodes 
International Journal of Wireless \& Mobile Networks (IJWMN) Vol. 4, No. 1, February 2012

\section{CONCLUSION}

In this our simulation work, the routing protocols: AODV and DSR are evaluated for the application oriented performance metrics like packet delivery fraction, average end-to-end delay, throughput and normalized routing load with increasing the ten number of mobile nodes up to 50. As we increase the number of nodes for performing the simulation of AODV and DSR routing protocols, number of sent, routing and delivered packets changes, hence the performance parameters changes.

As a result of our studies, we concluded that AODV exhibits a better performance in terms of packet delivery fraction and throughput with increasing number of mobile nodes due to its on demand characteristics to determine the freshness of the routes. It is proved that the AODV has slightly higher average end-to-end delay than DSR. Our result also indicates that as the number of nodes in the network increases AODV and DSR gives nearly constant throughput. Considering the overall performance, AODV performs well with varying network size.

\section{REFERENCES}

[1] J. Broch, D. A. Maltz, D. B. Johnson et.al.”, A Performance Comparison of Multi-Hop Wireless Network Routing Protocols," Proceedings of the Fourth Annual ACM/IEEE International Conference on Mobile Computing and Networking (MobiCom'98), October 25-30, 1998, USA,pp.25-30.

[2] S. R. Das, C. E. Perkins, and E. M. Royer, "Performance Comparison of Two On-Demand Routing Protocols for Ad Hoc Networks “, IEEE Personal Communications Magazine, Vol. 8, No. 1, February 2001, pp.16-29.

[3] David Oliver Jorg, "Performance Comparison of MANET Routing Protocols In Different Network Sizes”, Computer Networks \& Distributed Systems, University of Berne, Switzerland, 2003.

[4] K U Khan, R U Zaman and A. Venugopal Reddy,"Performance Comparison of On-Demand and Table Driven Ad HocRouting Protocols using NCTUns", Tenth International Conference on Computer Modeling and Simulation, 2008.

[5] Saurabh Gupta "Analysis of simulation of ad hoc on demand distance vector routing protocol", National Conference on Advanced Computing and Communication Technology ACCT-10.

[6] S. P. Setty et. al., "Performance evaluation of aodv in different environments", International Journal of Engineering Science and Technology Vol. 2(7), 2010, 2976-2981

[7] Azzedine Boukerche, "A Performance comparison of routing protocols for Ad Hoc Networks", Parallel Simulations and Distributed Systems Research Laboratory, University of North of Texas,0-7695-0990-8/01/\$10.00 (C) 2001 IEEE.

[8] Arun Kumar B. R., Lokanatha C. Reddy, Prakash.S.Hiremath, "Performance Comparison of Wireless Mobile Ad hoc Network Routing Protocols" IJCSNS International Journal of Computer Science and Network Security VOL.8 No.6, June 2008.

[9] S. Gowrishankar, et.al., "Scenario based Performance Analysis of AODV and OLSR in Mobile Ad Hoc Networks", Proceedings of the $24^{\text {th }}$ South East Asia Regional Computer Conference, November 18-19, 2007, Bangkok, Thailand.

[10] N Vetrivelan, Dr. A V Reddy, “ Performance Analysis of Three Routing Protocols for Varying MANET Size", Proceeding of the International MultiConference of Engineers and Computer Scientists 2008 Vol II, IMECS 2008,19-21, Hong Kong.

[11] Abdul Hadi Abd Rahman and Zuriati Ahmad Zukarnain, "Performance Comparison of AODV, DSDV and I-DSDV Routing Protocols in Mobile Ad Hoc networks", European Journal of Scientific Research, Vol.31 No.4 (2009), pp.566-576. 
International Journal of Wireless \& Mobile Networks (IJWMN) Vol. 4, No. 1, February 2012

[12] E. M. Royer, and C.K. Toh, "A Review of Current Routing Protocols for Ad Hoc Mobile Wireless Networks”, IEEE Personal Communications, Vol. 6, Issue 2, pp. 46-55, April 1999.

[13] NS -2, The ns Manual, Available at http: //www. isi.edu/nsnam/ns/doc.

[14] C. E. Perkins, E. M. Royer, and S. R. Das, "Ad Hoc On- Demand Distance Vector (AODV) Routing”, Internet Draft, draft-ietf- manet- aodv-10.txt, work in progress, 2002.

[15] Satya Ranjan Rath, "Study of performance of routing protocols for mobile Adhoc networking in NS-2”, NIT, Rourkela,2009.

[16] David B. Johnson and David A. Maltz, "Dynamic Source Routing in Ad Hoc Wireless Networks", Computer Science Department, Carnegie Mellon University, Avenue Pittsburgh, PA 15213-3891.

[17] Parma Nand and Dr. S. C. Sharma, "Performance study of Broadcast based Mobile Adhoc Routing Protocols AODV, DSR and DYMO," International Journal of Security and its Applications, Vol. 5 No. 1, January, 2011.

[18] Rashmika N Patel,” An Analysis On Performance Evaluation Of DSR In Various Placement Environments", Proceedings of the International Joint Journal Conference on Engineering and Technology (IJJCET 2010)

[19] Anuj K. Gupta, Dr. Harsh Sadawarti and Dr. Anil K. Verma, "Performance analysis of AODV, DSR \& TORA Routing Protocols," IACSIT International Journal of Engineering and Technology, Vol.2, No.2, April 2010 ISSN: 1793-8236.

[20] Santosh Kumar,S C Sharma, Bhupendra Suman, "Simulation Based Performance Analysis of Routing Protocols Using Random Waypoint Mobility Model in Mobile Ad Hoc Network", Global Journal of Computer Science and Technology.

[21] Rajesh Deshmukh, Asha Ambhaikar, "Performance Evaluation of AODV and DSR with Reference to Network Size”, International Journal of Computer Applications (0975 - 8887) Volume 11- No.8, December 2010.

\section{AUTHORS PROFILE}

Nilesh P. Bobade received M.Tech degree in Electronics Engineering from RTM Nagpur University, Nagpur, M.S., India. He received his B.E. degree in Electronics Engineering from RTM Nagpur University, Nagpur in year 1996. He is Assistant Professor in the Department of Electronics Engineering, BDCE, Sevagram, Wardha, M.S., India. He is a life member of Indian Socirty for Technical Education. He published research papers at National and International level. His research interests include embedded systems. And computer networks.

Mr. Nitiket N. Mhala is Associate Professor and Head in the Department of Electronic Engineering, Sevagram, India and he submitted his $\mathrm{PhD}$. He received his ME Degree from RM Institute of Research and Technology, Badnera, Amravati University and B.E. Degree from Govt. College of Engineering, Amravati, Amravati University. He published a Book Entitled PC Architecture and Maintenance. He is a member of Institute of Electronics and Telecommunication Engineer (IETE). His area of interest spans Data communication, Computer network and Wireless Ad hoc networks. He published research papers at National and International level.
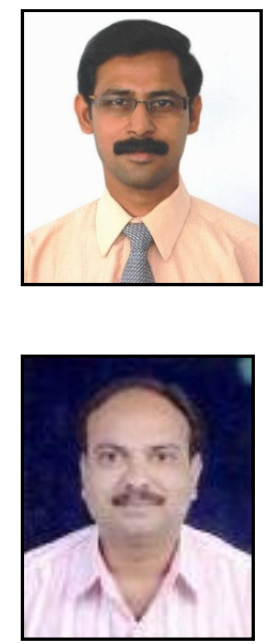